\title{
CODE OF ETHICS AND QUALIFICATION TESTS
}

\author{
Iuliia Nozdracheva \\ Teacher, RUDN University, Law Institute Foreign Languages Department, \\ RUSSIAN FEDERATION, \\ ylkaxd66@yandex.ru
}

\begin{abstract}
This article explores issues faced by interpreters from the point of cross-cultural interaction because it is not enough to enhance only speaking or listening skills. Linguistic competence presupposes a perpetual broadening cultural experience and understanding something outside the scope of the language. In some countries, for instance, the USA special accreditation services have been established responsible for decent service provision.

Norms are vague but at the same by analyzing different sources, codes of ethics and practice, qualification tests it is possible to unify them and develop a unified form for understanding the meaning of interpreters competence. Undoubtedly, interpreters shall be held liable for their actions. Interpreters in such settings as judicial one receive personal information which must not be revealed, so the high level of confidentiality is strictly required. It is worth denoting that not everywhere the concrete requirements have been set towards interpreters' competence.

The aim of this article is to analyze the situations in different countries and compare Russia with them, because in Russia the demands regarding what qualification tests must be taken by interpreters are vague. The particular attention is drawn to what aspects must be included in such tests and how they must be undertaken.

The topicality of this research is actual within the framework of globalization interpreters and specialists engaged in verbal communication face cultural barriers based on the lack of knowledge how to behave in a court session. Besides, business ethics and the moral standards should be taken into account, so they have had a large impact on interpreting activities in a court session.
\end{abstract}

A number of differences have been identified and some conclusions have been made. Concluding remarks provide recommendations regarding skills, moral qualities and amount of knowledge.

Keywords: Translation and Interpreting Industry, Code of Ethics, Translator and Interpreter's Training.

\section{INTRODUCTION}

The current multilingual landscape of the world increases the role of interpreters and translators in the course of communication mediated across native speakers of different languages. Scholars traditionally pay a specific attention to the Code of Ethics role within the Translation and Interpreting activities.

Scholars consider current state of affairs and further developments of the Code of Ethics standards and features (Lee, Yun, 2020), emphasize the status of ethics within the formation of translator and interpreter's competence (Oraki, Tajvidi, 2020, Moorkens, Rocchi, 2020) explore collaboration among various specialists who engage in interpreting practices within particular domains (Lutskovskaia et al., 2019; Zhang et al.,2020), distinguish the concept of translator ethics development within professional and non-professional 
settings (Lambert, 2020; Monzó-Nebot, Wallace, 2020), specify the potential of ICT tools for representation of interpreters' ethics phenomenon in the course of their professional activities (Atabekova, 2017,2018).

Recent studies of translators and interpreters' work within the emergency settings shed new light of the Code of Ethics implementation into the above specialists' operational activities during the natural disasters (O'Brien et al., 2018), and forced migration (Atabekova et al., 2019).

The above data have put on the agenda of the importance of applied approach to the Code of Ethics. Such an approach should consider this Code within the multidisciplinary paradigm of the Translation and Interpreting Industry development.

The respective goal is reached through analysis of codes of ethics of different countries and tasks themselves fixed in qualification tests, through comparison them with the practice of the Russian Federation.

\section{MATERIALS AND METHODS}

The study explored some national Codes of Ethics, professional associations rules and requirements, empirical data from open digital sources.

The study used theoretical analysis of relevant academic and regulative sources, and considered empirical data by the techniques of their observation and comparative investigation of major provisions and statements.

\section{RESULTS AND DISCUSSION}

The code of ethics defines the norms and rules of conduct for members of the community where interpreters and translators are the key figures involved in the implementation of their professional activities, based on moral and ethical values and professional standards. Non-compliance with ethical principles can serve as a ground for moral censure of violators.

The Code of Ethics covers issues that are outside the scope of current legislation, therefore it may supplement the provisions of agreements concluded by participants. The provisions of the Code, within the applicable limits, are addressed to all participants in translation activities: companies engaged in interpreting activities and their heads, translators and interpreters who carry out various types of work (translators and interpreters, guides, sign language interpreters, audio-visual translators, social translators, etc.), editors and proofreaders ( Felberg, Skaaden, 2012).

The translator or translation company has the right to reject an order for ideological or ethical reasons in advance before accomplishing the tasks. If such reasons appeared in the course of the performance of official duties, then the termination of work is permissible only in those cases when the translation is contrary to applicable law and order.

Interpreters should seek ways to eliminate imperfections and to deepen professional skills. Company strives to apply advanced technologies in its work related to translation and interpreting industries.

As a rule, the work of a translator remains invisible to the general public, and its importance is underestimated. Any company responsible for interpreting services provision should willingly promote and support legislative initiatives aimed at industry development, thereby considerably increasing the prestige of the profession, through development industry standards and preparation of documents, as well as initiatives that attract the attention of state and municipal authorities, public and business communities to the problems are faced by members of interpreting community and those who belong to it.

As an example can be taken the professional code provided by the Union of Translators of Russia which unites translators, teachers, interpreters, judicial and simultaneous interpreters, media translators, as well as experts in the fields of lexicography, theory and history of translation, specialists in different genres and spheres of translation and interpreting and its branches may operate in different regions. The abovementioned organization is also a permanent member of the International Federation of Translators. The professional code was adopted on 14th of May, 1998 by the third Congress of the Union of Translators of Russia. It provides for a compliance of a range of norms:

A translator must adhere to and demand compliance with all the norms and rules provided for by national and international law, which he / she is obliged to follow according to the Union of translators of Russia.

It is disgraceful for a translator to accept terms and conditions that infringe upon his or her professional and human dignity. In addition to this, if an access to comfortable conditions for interpreting or translation activities are not provided the interpreter is not obliged to agree on such terms due to the fact that such 
circumstances can harm the quality of translation, or do not guarantee the high quality of translation and do not meet the interest of the professional community.

The translator must take into account the legal rights of the authors of the original texts and adhere to the principles of professional solidarity, avoid unfair competition, and also not agree to the terms that do not correspond to those that have been agreed upon between the parties beforehand. He or she is obliged to guarantee the confidentiality of the information which means she or he is not entitled to divulge information to the third parties. In the process of working as part of community, the translator must comply with the generally accepted rules for members of this group. The translator is responsible for the quality of the translation, regardless of the terms of the contract concluded with the customer.

Besides, moral norms for compliance have also been established for translator and interpreters. The may differ from each other when compared with different countries, although some basic principles exist which can be considered as conventional ones and generally accepted worldwide. Some provisions are inserted into so called moral code of interpreting:

The translator is not considered as any client's interlocutor. It converts spoken or written text created in one language into the same text in another language. The text as the source of information is inviolable for the translator. The translator does not have the right to distort the meaning and composition of the text while providing translation or interpreting services, or to change its volume, except the cases when the additional tasks are needed and presuppose transformations of any kind but these requirements are set only by the customer. In the course of work, any translator must adhere to the rules of ethics of oral communication, business etiquette, respecting the freedom of the client's personality.

In certain cases, while dealing with consecutive or simultaneous ways of interpreting, an interpreter becomes a person who also has diplomatic powers. He or she has the right to eliminate some inaccuracy in the source text by clarifying what has been meant, while functioning as an auxiliary mechanism in supporting diplomatic relations, but does not have to protect the interests of a certain party. A translator should not react emotionally to individual defects in the speaker's speech and reflect them in the translation (Felberg, Skaaden, 2012).

In other cases, the translator has no right to interfere in the relations of the parties, as well as to mark his or her own position on the content of the translated text. The translator must take care of his health, because the quality of translation depends largely on the physical condition of a translator. The translator should immediately signal his / her inadequate competence, i.e. the insufficient level of knowledge and experience necessary for effective translation activities, and correct the errors made by him or her instead of concealing them in the process of translation, it is highly essential and relevant for conducting successfully interpreting activities.

As part of the professional ethics of the translator, it is worth highlighting a few more norms related to behavior of a translator in different situations where assistance provided by an interpreter or a translator is needed: The translator must be fully adapted to the situation of translation, which implies, in particular, respect for decency and neatness in everything, nonverbal communication is not exception.

Scholars underline, that the translator should not attract too much attention to himself or herself being the center of attention is not the priority, vice versa it is necessary to act only as a mediator of communication, a "link or channel for transferring information" (AUSIT, 2012). An adequate assessment of the work must be given by a translator on his or her own and he or she must independently control the volume of his or her work and should not take everything at once since this will inevitably leave a print on the quality of the work accomplished. Under no circumstances the translator is not entitled:

- To attract too much attention to himself or herself

- To use ways of demonstrating signs of irritation and excessive emotionality appropriate and stable behavior is heartily welcomed

- To demonstrate your attitude toward the materials given, even if they are controversial

- To provide interpreting of the speaker's speech in the third person: "He says that...especially in the presence of the speaker

- To violate the rules and protocols` provisions

- To engage in private discussions and negotiations 
- To negotiate on sensitive topics related to the organization or firm and its employees

- To be distracted by third-party conversations by using a mobile phone. (all gadgets must be turned off in the course of interpreting activities.

One of the most important problems that a translator may face in both oral and written translation is the usage of professional slang in speech. This issue is regulated by business etiquette, which allows the use of slang in the communication of specialists, but excludes it if non-experts may be among the communicants or communication intermediaries. The translator may also have difficulties translating special terminology. However, the translator inevitably has to work with this kind of vocabulary, so it is necessary to actually get acquainted with the terminology related to a specific translation act. (Alekseeva 2004).

As for examination procedures and tests in Russia are even sometimes not carried out, so a degree in linguistics or interpreting is officially recognized. In order to become a competent interpreter a person should decide for himself or herself how to enhance knowledge in this field. Not so much trainings exist in Russia but some of them allow to improve the level of language and obtain extra knowledge regarding non-verbal communication, etiquette, code of ethic and etc. Some freelance assignments and written tests aimed at checking language proficiency have been analyzed.

Qualified court interpreters possess native-like mastery of both English and the target language and have the ability to do consecutive, simultaneous and sight interpreting in a courtroom setting. To increase their proficiency of the English language, applicants may find it helpful to take an English course at a college or university and study vocabulary-building books found in the reference sections of libraries and bookstores. To improve knowledge of court-related legal terminology, there are many excellent glossaries and other resources available to interpreters in publications and on organizational websites such as: http://www.ncsc.org and http://www.najit.org. Applicants can also reference a copy of the UCS Court Interpreter Manual and Code of Ethics which contains a legal glossary and extensive practical information useful to both current and prospective court interpreters that is available on the NYS Unified Court System's website at: http://www.nycourts.gov/courtinterpreter/index.shtml.

Such materials and recommendations can be used for candidates who would like to enhance language proficiency from different angles.

The most useful tasks which may serve as a model applied for teaching potential interpreters and translators (these material taken from written and oral tests provided by Unified Court System of State of New York) are exercises to play a real role of interpreter in a police interview between a Police officer who speaks English and a suspect who speaks the other language. It is allowed to take notes, to ask for repetition. Sight translations and interpreting of statements must be included in tests and examination procedure due to the fact they are the most effective tool for liquidating imperfection and enhancing language proficiency. After enhancing this knowledge an interpreter may bring about objectives regarding fluency in non-verbal communication, how to behave, what position to take in a courtroom or the other place.

\section{CONCLUDING REMARKS}

It is worth emphasizing again that it is essential for a translator timely inform about their lack of competence and the facts of misunderstanding of the source text.

Summing up, representatives of any profession have certain norms and rules of behavior, a certain business etiquette. By taking these norms into account any profession increases its status in society.

Thus, it is very important for a translator to know and observe professional etiquette in order to show their intelligence and competence.

Furthermore, the above issues are supposed to be a mandatory part of university-based degree training for professional interpreters and translators that is supposed to avoid lecturing and to run through simulations and gaming.

\section{REFERENCE LIST}

Alekseeva, I.S. (2004). Translator and Interpreter education in Russia. In: Introduction in Translation Studies. Saint Petersburg, Russia: Akademiya, pp. 42-47. 
Atabekova, A. (2017). ICT-based Visualization for Language and Culture Mediation Skills Training: Addressing Societal Needs. Procedia- Social and Behavioral Sciences, 237, 209-215.

Atabekova, A. (2018). ICT Tools for Interpreters: Is Academia ready for Industry Digital Development? 12th International Technology, Education and Development Conférence (INTED), Valencia, SPAIN ny6;i.: MAR 05-07,2018, pp. 8708-8712

Atabekova, A., Nozdracheva, I., Semenova, A. (2019). Language Issues: Interpreting and Translation within Forced Migration (2015-2019) European Landscape, Russian Features. Monograph. Moscow, RUDN University.

AUSIT. (2012). AUSIT code of ethics and code of conduct. Retrieved 11 April, 2013, from http://ausit.org/AUSIT/Documents/Code_Of_Ethics_Full.pdf

Felberg, T., Skaaden, H. (2012). The (de)construction of culture in interpreter-mediated medical discourse. Linguistica Antverpiensia, 11, 95-112.

Lambert, J. (2020). Professional translator ethics. In The Routledge Handbook of Translation and Ethics (pp. 165-179). Routledge.

Lee, H., Yun, S. W. (2020). How can we improve the codes of ethics for translators? Babel, 66(4-5), 706718.

Lutskovskaia, L., Atabekova, A., Zvereva, E., Kalashnikova, E., Gorbatenko, O. (2019).A pilot study of language and culture mediation in medical interpreting at border crossing points in Moscow, Russia. Heliyon, 5(2),e01208

Monzó-Nebot, E., Wallace, M. (2020). New societies, new values, new demands: Mapping non-professional interpreting and translation, remapping translation and interpreting ethics. Translation and Interpreting Studies. The Journal of the American Translation and Interpreting Studies Association, 15(1), 1-14.

Moorkens, J., Rocchi, M. (2020). Ethics in the translation industry. In The Routledge Handbook of Translation and Ethics (pp. 320-337). Routledge.

NYS Unified Court System's website (n/d). http://www.nycourts.gov/courtinterpreter/index.shtml.

O’Brien, S., Federici, F., Cadwell, P., Marlowe, J., Gerber, B. (2018). Language translation during disaster: A comparative analysis of five national approaches. International journal of disaster risk reduction, 31 627-636.

Oraki, A., Tajvidi, G. (2020). Training Translators and Interpreters: The Need for a Competence-based Approach in Designing University Curricula. Iranian Journal of English for Academic Purposes, 9(2), 42-56.

Zhang, C. X., Crawford, E., Marshall, J., Bernard, A., Walker-Smith, K. (2020). Developing interprofessional collaboration between clinicians, interpreters, and translators in healthcare settings: outcomes from face-to-face training. Journal of Interprofessional Care, 1-11.

Zhang, C. X., Marshall, J., Bernard, A., Walker-Smith, K. (2020). Development and evaluation of interprofessional e-learning for speech pathologists, interpreters and translators. Translation \& Interpreting, 12(1), 142-158. 